\title{
Determination of the magnitudes and values for groundwater recharge from Taiwan's paddy field
}

Received: 30 August 2004 / Accepted: 3 March 2005

(C) Springer-Verlag 2005

\begin{abstract}
Flooded paddy fields have many functions, including not only rice production, and ecological and environmental conservation. This work estimates the extent of paddy field infiltration in Taiwan by adopting a one-dimensional Darcy-based soil/water balance model SAWAH (Simulation Algorithm for Water Flow in Aquatic Habitats). A $10 \mathrm{~cm}$ thick plow sole layer with a hydraulic conductivity of $0.03 \mathrm{~cm} /$ day, coupled with the soil texture and irrigation data obtained from 15 irrigation associations, is used to estimate the volumetric amount of annual infiltration in Taiwan. Simulation results from SAWAH indicate that the plow sole layer controls the movement of infiltrated water, with a rate about 1.8 billion cubic meters annually. The estimated infiltration rate of 1.8 billion $\mathrm{m}^{3} / \mathrm{yr}$ comprises more than $40 \%$ of the annual infiltration recharge to ground water in Taiwan. Additionally, the amount of infiltration recharge to groundwater is equivalent to 20 billion Taiwan dollars NT $\$$ (or 0.65 billion US\$) while the yearly rice crop production is 35 billion NT\$ (or 1.13 billion US\$). It is evident that the infiltration from rice paddy is of great importance to the economy, environment, and water resources conservation in Taiwan.
\end{abstract}

Keywords Infiltration - Irrigation - SAWAH · Plow sole · Geographical information system

\section{Introduction}

Flooded paddy rice fields have many functions including rice production, ecological and environmental conserva-

C.-W. Liu $(\bowtie)$

Department of Bioenvironmental Systems Engineering,

National Taiwan University,

No. 1, Sec. 4, Roosevelt Road,

Taipei, 106, Taiwan, ROC

e-mail: 1cw@gwater.agec.ntu.edu.tw

C.-H. Tan · C.-C. Huang

Agricultural Engineering Research Center,

No. 196-1, Chung Yuan Road,

Chung-Li 320, Taiwan, ROC tion. A flooded paddy field can also be considered as an artificial wetland and as a major source of groundwater recharge (Tzia 1993).

Groundwater recharge from paddy rice fields that can be estimated via a field water balance equation:

$I+R=E+T+S+P+D+d w$

where $I$ is the irrigation supply; $R$, rainfall; $E$, evaporation; $T$, transpiration; $S$, lateral seepage; $P$, percolation; $D$, surface drainage or runoff; $d w$ is the change in ponded water depth or water storage in the soil profile; all in $\mathrm{mm} /$ day.

Percolation that is the vertical movement of water beyond the root zone to the water table while lateral seepage is the movement of subsurface flow from one field to the another (IRRI 1965). Both of which are considered to be a primary loss for farmers. However, as water percolates into an aquifer, it can be reused for irrigation or other purpose by pumping. Therefore, percolation and lateral seepage can no longer be considered as irrigation losses for water resources management in Taiwan.

Many factors influence infiltration from rice fields, including soil texture and structure, top and subsoil thickness, flooded water depth, the water and soil temperature and salinity, the depth of ground water table, and other topographical conditions (Wickham and Singh 1978). Farmers puddle their paddies to reduce percolation loss during transplanting. After long-cultivation periods, a 5- to $10-\mathrm{cm}$ plow sole layer (or hard pan), $20-30 \mathrm{~cm}$ below the ground surface, will form to prevent the infiltration of ponded water from draining further downward. The plow sole layer complicates infiltration by making it a variable saturated flow problem. Several numerical models based on characteristic of paddy fields in Southeast Asia have been developed (Belmans et al. 1983; McMennamy and O'Tool 1983; ten Berge et al. 1992; Bouman et al. 1994; Wopereis et al. 1994).

A one-dimensional simulation algorithm for water flow in aquatic habitats (SAWAH) model developed by ten Berge et al. (1992, 1995) has been extensively used in Asian nation including Taiwan (Liu et al. 2001, Chen 
et al. 2002, Huang et al. 2003). This model can simulate saturated and unsaturated flow that simultaneously occur in varying soil profile sections in both upland and lowland, rainfed and irrigated environments where soils are layered and hydrology is highly dynamic with variable ground water and volumetric soil water content. Because of its high degree of detail, SAWAH has been adopted to evaluate water-use efficiency and feasibility of groundwater recharge under various soil-water conditions (Bouman et al. 1994; Chen et al. 2002).

This study attempts to quantitatively evaluate the infiltration rate of Taiwan's paddy fields using SAWAH, under different soil texture conditions. The simulated infiltration rates coupled with geographical information system (GIS) and the irrigation schedule are employed to estimate the annual amounts of infiltration and effective groundwater recharge in Taiwanese paddy field.

\section{Materials and methods}

\section{SAWAH model}

The one-dimensional soil/water balance model SAWAH developed by ten Berge et al. (1992) can be used to simulate the water movements within multiple saturated/unsaturated layers in a ponded condition. The required input data are the soil/water retention function, unsaturated hydraulic conductivity function, and the boundary conditions, including levels of irrigation water, and the depth of the ground water table. The daily infiltration rate for different irrigation duration periods can be determined according to the given input data. The areal annual infiltration can then be estimated by the following equation:

$$
\text { Areal annual infiltration }\left(\mathrm{m}^{3}\right)=\sum P\left(A_{1} f_{1}+A_{2} f_{2}\right) \times 10
$$

where $P$ is the infiltration rate in $\mathrm{mm} /$ day computed with SAWAH; $A_{1}$ and $A_{2}$ denote the irrigation areas in hectares for the first and second crop periods, respectively; $f_{1}$ and $f_{2}$ represent irrigation durations in days within the first and second crop periods, respectively; and 10 is the unit conversion factor. The data of $A_{1}, A_{2}, f_{1}$ and $f_{2}$ were obtained from the annual reports of 15 irrigation associations compiled by the Agriculture Engineering Research Center.

\section{Study area}

The study area was approximately 380,000 ha, covering all paddy fields in Taiwan (Fig. 1). Fifteen irrigation associations manage this 380,000 ha of paddies. The 15 irrigation associations are divided geographically; those in the northern part are Pai-Zi, Tao-Yuan, Shih-Men, Hsin-Chu, and Miao-Li; those in the central part are Tai-Chung, Nan-Tou, Chang-Hua and Yu-Lin; those in the southern part are Chia-Na, Kao-Shiung and Ping-Tung, and those in the eastern part are E-Land, Hua-Lien and Tai-Tung. Taiwan has two rice-growing seasons annually. The first crop season is from February to July, and lasts for 120-140 days. The temperature gradually increases as the season changes from spring to summer. The second crop season is from August to the following January, and lasts for 110-150 days. This crop season includes the end of the summer, and continues through autumn to winter; the temperature decreases from high to low.

The rice growth period is divided into five stages, including transplanting, effective tillering, booting, blooming and maturity. The durations of each the stages are approximately 15, 35, 25, 15 and 20 days, in that order. The flooded water is drained in the maturity stage, thus the 20 days of the maturity stage is subtracted from the rice growth period in the estimation of the infiltration recharge to groundwater.

\section{Paddy environment}

As illustrated in Fig. 2, the soil/water distribution of a rice paddy can be divided into four layers (Wopereis et al. 1994):

1. Variable head of irrigated or precipitated ponded water;

2. A low flow resistant muddy layer;

3. A high flow resistant plow sole layer (or hard pan); and 4. A non-puddled subsoil layer.

The heterogeneous four-layer soil complicates the infiltration process since the depth of the standing water gradually decreases as the water moves downward. The muddy layer, which contains a mixture of soil particles and irrigation water, becomes saturated. Additionally, the plow sole layer, which has a low-hydraulic conductivity retains the infiltrated water within the muddy layer and remains saturated. Therefore, the highly hydraulically conductive non-puddled subsoil layer receives less water and is unsaturated. Detailed data on the hydraulic characteristics of each layer is necessary to simulate infiltration in the paddy.

The Irrigation Associations in Taiwan employ a rotational irrigation scheme to maximize utilization of limited water resources. The associations manage and provide sufficient irrigation water by specific sequential irrigation time steps. The irrigation water is utilized for rice uptake, evapotranspiration and infiltration, and the ponded irrigation water is no longer supplied as the rice matures.

\section{Determining soil/water parameters}

The initial field preparation for a paddy sector of 50 ha requires 3-5 days of flooding, sufficient time to puddle and soften the topsoil. Soil texture and composition after initial field preparation are obtained from the Taiwan Soil Survey Data System developed by National Chun-Hsin University. This system provides 
Fig. 1 Geographic distribution of paddy areas of 15 irrigation associations in Taiwan
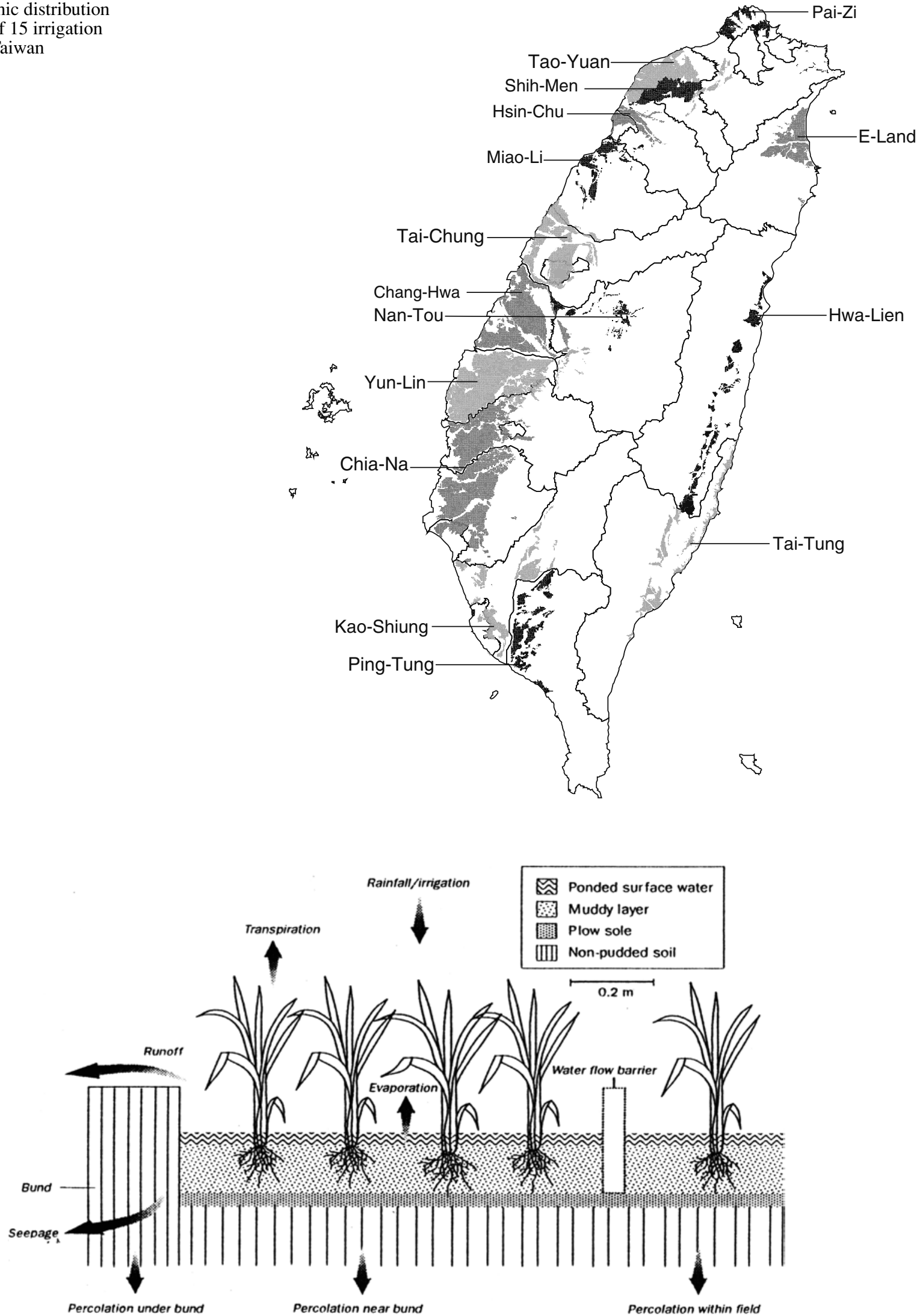

Fig. 2 A schematic diagram of water movement in a paddy environment (after Wopereis et al. 1994) 
Table 1 Hydraulic characteristics of different soil types for the Simulation Algorithm for Water Flow in Aquatic Habitats (SAWAH) simulation

\begin{tabular}{lllllll}
\hline Soil type & $\begin{array}{l}\text { Saturated hydraulic } \\
\text { conductivity }\left(K_{\mathrm{s}},\right. \\
\mathrm{cm} / \text { day })\end{array}$ & $\begin{array}{l}\text { Soil characteristic } \\
\text { parameters } \\
\alpha\left(\mathrm{cm}^{-1}\right)\end{array}$ & $\begin{array}{l}\text { Soil characteristic } \\
\text { parameters } \\
a\left(\mathrm{~cm}^{2.4} / \text { day }\right)\end{array}$ & $\begin{array}{l}\text { Soil characteristic } \\
\text { parameters } h_{\max } \\
(\mathrm{cm})\end{array}$ & $\begin{array}{l}\text { Soil characteristic } \\
\text { parameters } \gamma \\
(\text { dimensionless })\end{array}$ & $\begin{array}{l}\text { Saturated water } \\
\text { content } \\
\theta_{\mathrm{s}}(\mathrm{v} / \mathrm{v} \%)\end{array}$ \\
\hline Gravel & 300.0 & 0.1385 & 0.63 & 90.0 & 0.045 & 36.50 \\
Sand & 110.0 & 0.0821 & 3.30 & 125.0 & 0.0366 & 35.00 \\
Fine sand & 50.0 & 0.0500 & 10.90 & 175.0 & 0.0255 & 36.40 \\
Loamy sand & 26.5 & 0.0395 & 16.40 & 200.0 & 0.0299 & 43.90 \\
Sandy loam & 12.0 & 0.0240 & 26.50 & 300.0 & 0.0186 & 50.40 \\
Silty loam & 6.50 & 0.0200 & 47.30 & 300.0 & 0.0165 & 50.90 \\
Loam & 5.00 & 0.0231 & 14.40 & 300.0 & 0.0164 & 50.30 \\
Sandy clay & 23.50 & 0.0353 & 33.60 & 200.0 & 0.0101 & 43.20 \\
loam & & & & & 0.0108 & 47.50 \\
Silty clay loam & 1.50 & 0.0237 & 3.60 & 300.0 & 0.0059 & 50.70 \\
Silty clay & 1.30 & 0.22 & 0.0480 & 28.20 & 50.0 & 0.0043 \\
Clay & 0.0380 & 4.86 & 80.0 & 54.00 \\
\hline
\end{tabular}

0-30, 30-60, 60-90 and 90-150 cm digital soil texture maps. The relationship between unsaturated hydraulic conductivity $(K)$ and pressure head $(h)$ can be expressed as

$K(h)=K_{s} \mathrm{e}^{\alpha h} \quad$ at $\quad h \geq h_{\max }$

$K(h)=a[h]^{-1.4}$ at $h<h_{\max }$

where $\alpha\left(L^{-1}\right), h_{\max }(L)$ and $a\left(L^{2.4} T^{-1}\right)$ are the empirical soil characteristic parameters.

The soil water content $\theta$ relationship with a pressure head is adopted from Driessen (1986), namely:

$h(\theta)=-\exp \left[\left(-\frac{1}{\gamma} \ln \frac{\theta}{\theta_{s}}\right)^{\frac{1}{2}}\right]$

where $\gamma$ is a dimensionless parameter related to the soil texture, $\theta_{\mathrm{s}}$ is saturated soil water content.

Table 1 lists the detailed hydraulic parameters of various types of soil used in the SAWAH simulation. The plow sole layer, which exhibits a very high flow resistance, is the key parameter controlling water infiltration. The thickness of the plow sole layer is assumed to be $10 \mathrm{~cm}$ and it is assumed to be positioned $20-30 \mathrm{~cm}$ below the ground surface, since the depth of topsoil in paddies that have applied mechanical cultivation methods is approximately $20 \mathrm{~cm}$. The saturated hydraulic conductivity of the plow sole is about $0.03 \mathrm{~cm} /$ day (Chen and Liu 2002). The simulated region is discretized into 10 grids representing the subsoil profile. The pressure head at the top of the plow sole is set as the upper boundary condition, and is the sum of the muddy layer depth and the ponded water depth. The plow sole layer is discretized into two grids, while the non-puddled soil layer is divided into eight grids. Figure 3 shows the layout of the numerical grids. The initial soil water contents of these grids are assigned to $2 / 3$ of their field capacities $(2 / 3 \mathrm{FC})$.

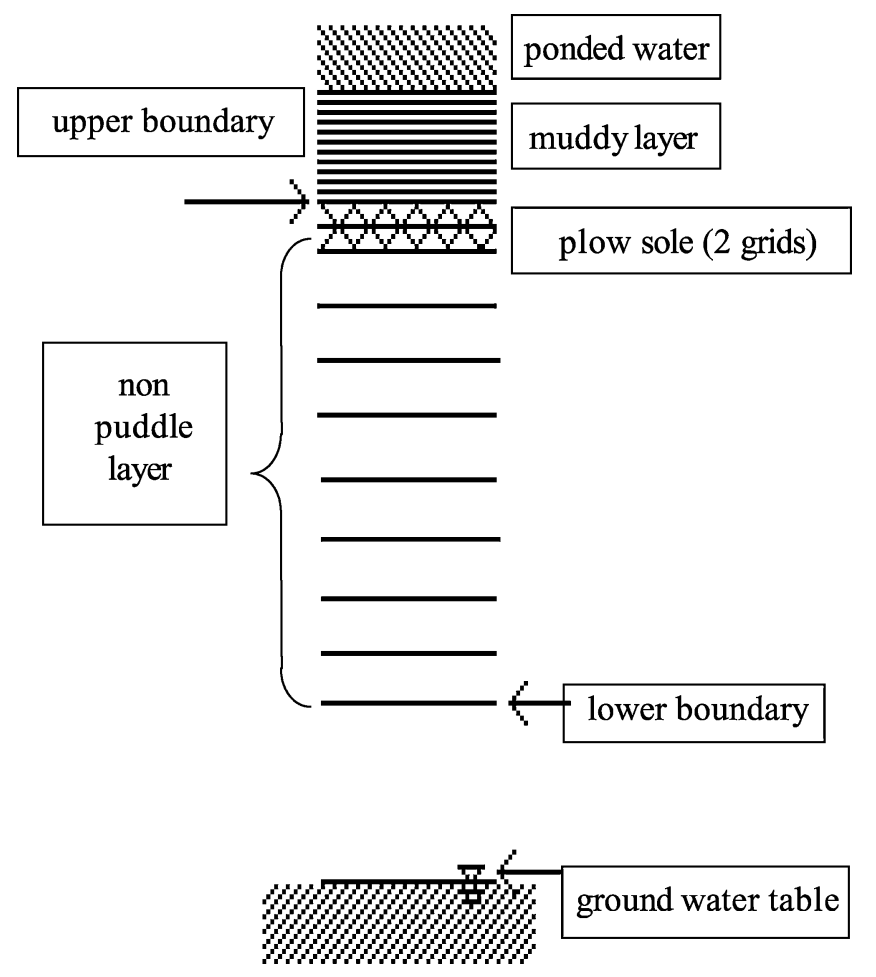

Fig. 3 A schematic numerical grid layout of infiltration in a paddy field

\section{Results and discussion}

\section{SAWAH simulation}

The $0.03 \mathrm{~cm} /$ day hydraulic conductivity of plow sole combined with the digital soil texture map of $0-30,30-60$, 60-90 and $90-150 \mathrm{~cm}$ and are adopted for SAWAH simulation. The simulated infiltration rate varies from 3.2 to $4.4 \mathrm{~mm} /$ day. The variation is mainly caused by the different types of soil texture below the plow sole layer (i.e. at $30-60 \mathrm{~cm}$ below the ground surface). To facilitate 
Table 2 Simulated infiltration flux through plow sole for various soil types in the irrigation area

\begin{tabular}{ll}
\hline Soil type & Infiltration flux $(\mathrm{mm} /$ day $)$ \\
\hline Clay & 3.2 \\
Loam & 3.5 \\
Silty loam & 3.6 \\
Loam sand & 3.7 \\
Fine sand & 4.1 \\
Sand & 4.4 \\
\hline
\end{tabular}

the areal infiltration estimation, Table 2 lists the simulated infiltration rates of six type soils at depth $30-60 \mathrm{~cm}$ commonly found in the 15 irrigation associations.

\section{Areal annual infiltration}

The amount of annual infiltration of the service area of 15 irrigation associations can be computed via Eq. (2) using the Geographic Information System that overlays the digitized soil texture data of the four-layer soils and the corresponding infiltration rate simulated by SAWAH.

Table 3 presents the estimated annual infiltration from 15 irrigation associations. The total amount is $18 \times$ $10^{8} \mathrm{~m}^{3} / \mathrm{yr}$ which comprises $40 \%$ of the annual groundwater recharge in Taiwan. Several studies have determined that the quantity of overall annual infiltration in Yu-Lin county ranges from 455 to 489 million cubic meters (Jang 1996; Liu and Chen 1997; Chaing and Ouyang 1996). Meanwhile, the amount of annual infiltration from paddy fields estimated using the SAWAH model is approximately 150 million cubic meters, contributing over $30 \%$ of the overall annual infiltration in Yun-Lin county. Additionally, in the year of 2000, a moderate draught occurred in Taiwan. Irrigation water was transferred for domestic and industrial uses. About half of the rice paddies were left fallow. Based on the statistics of rice production in Taiwan (Council of Agri-

Table 3 Estimated annual infiltration from 15 irrigation associations

\begin{tabular}{lll}
\hline Irrigation association & Irrigated area in ha & $\begin{array}{l}\text { Annual infiltration in } \\
10^{8} \mathrm{~m}^{3}\end{array}$ \\
\hline E-Land & 18,698 & 1.43 \\
Pai-Zi & 4,912 & 0.17 \\
Tao-Yuan & 24,952 & 1.37 \\
Shin-Men & 11,997 & 0.30 \\
Hsin-Chu & 6,543 & 0.46 \\
Miao-Li & 10,895 & 0.59 \\
Tai-Chung & 31,233 & 2.21 \\
Nan-Tao & 13,244 & 1.13 \\
Chang-Hwa & 49,820 & 3.96 \\
Yun-Lin & 62,851 & 1.50 \\
Chia-Na & 78,422 & 2.10 \\
Kao-Shiung & 18,414 & 0.40 \\
Ping-Tung & 25,444 & 1.19 \\
Tai-Tung & 13,498 & 0.17 \\
Hwa-Lien & 12,457 & 0.99 \\
Total & 383,380 & 17.97 \\
\hline
\end{tabular}

culture 2001), the rice planting areas in the first and second crop periods were reduced to 195,059 and 144,892 ha, respectively. Using the same estimation method, the simulated ground water recharges from rice paddies in the first and second crop periods fell to $5.2 \times 10^{8}$ and $3.6 \times 10^{8} \mathrm{~m}^{3}$, respectively. The amount of annual groundwater recharge from rice paddies reduced to $8.8 \times 10^{8} \mathrm{~m}^{3}$ or $49 \%$ of the normal groundwater recharge rate from paddy field. The reduction of rice planting area has caused a significant decrease of groundwater recharge. Infiltration from paddy fields is thus an essential source of groundwater recharge and is important to water resources conservation.

The average water price for six proposed dams is about $11.15 \mathrm{NT} \$ / \mathrm{m}^{3}$ (or $0.60 \mathrm{US} \$ / \mathrm{m}^{3}$; Agricultural Engineering Research Center 2001). Multiplying it to the amount of annual infiltration yields a total value of NT\$ $20 \times 10^{9}$ (or US $\$ 6.46 \times 10^{8}$ ), while the yearly rice crop production is NT $\$ 35 \times 10^{9}$ (or US\$ $1.13 \times 10^{9}$ ). It is evident that the infiltration from rice paddy is also of great importance to the economy.

\section{Conclusion}

Flooded paddy fields serve many functions, such as rice production, and ecological and environmental conservation. A one-dimensional, Darcy-based soil/water balance model SAWAH was adopted to evaluate the extent of infiltration from the paddy fields in Taiwan. A $10-\mathrm{cm}$ thick plow sole layer with a hydraulic conductivity of $0.03 \mathrm{~cm} /$ day, coupled with the soil texture and irrigation data obtained from 15 irrigation association, was used to evaluate the volumetric amount of annual infiltration in Taiwan. Simulation results from SAWAH indicated that the plow sole layer controls the movement of infiltrated water recharge to ground water aquifer. The simulated ground water from rice paddies is 1.8 billion cubic meters annually or equivalent to 20 billion NT\$ (or US\$ $5.71 \times 10^{8}$ ). It is evident that the infiltration from rice paddy is of great importance to the economy, environment and water resource management in Taiwan.

Acknowledgements The authors would like to thank the National Science Council and the Council of Agriculture of the Republic of China for financially supporting this work under Contract Nos. NSC-92-2313-B-003-104 and No. 92-NouFar-8.2- Lin-01(07), respectively

\section{References}

Agricultural Engineering Research Center (2001) Feasibility study the release of irrigation water to non agricultural sector use from Chia-Na, Tai-Chung, Shih-Men and Tao-Yuan irrigation associations by adjusting the cultivation plan. Research Report of Agricultural Engineering Research Center, pp 7-9

Belmans C, Wesseling JG, Feddes RA (1983) Simulation model of the water balance of a cropped soil: SWATRE. J Hydrol 63:271-286

Bouman BAM, Wopereis MCS, Kroff MJ, ten Berge HFM, Tuong TP (1994) Water use efficiency of flooded rice fields. (II) Percolation and seepage losses. Agric Water Manage 26:291-304 
Chaing L, Ouyang S (1996) Preliminary evaluation of groundwater and water balances in Yun-Lin, Taiwan. In: Proceedings of Chou Shui River Alluvial Fan Groundwater and Hydrogeology Conference, pp 181-206

Chen SK, Liu CW (2002) Analysis of water movement in the paddy rice fields. (I) Experimental studies. J Hydrol 260:206-215

Chen SK, Liu CW, Huang HC (2002) Analysis of water movement in paddy rice fields. (II) Numerical simulations. J Hydrol 265:259-271

Council of Agriculture (2001) Year book of rice production in Taiwan. Government Press, Taipei, Taiwan, ROC

Driessen PM (1986) The water balance of the soil. In: van Keulen, H., Wolf, J. (eds) Modeling of Agricultural Production: Weather, Soil and Crops. Simulation Monographs. Pudoc, Wageningen, pp 76-116

Huang HC, Liu CW, Chen SK, Chen JS (2003) Analysis of percolation and seepage through paddy bunds. J Hydrol 284:13-25

IRRI (1965) Annual Report 1964. International Rice Research Institute, Los Banos, Philippines, pp 335

Jang CS (1996) Three dimensional numerical simulation of the groundwater flow in Yun-Lin, Taiwan. MS Thesis, Department of Agricultural Engineering, National Taiwan University, Taipei, Taiwan, pp 6-17

Liu CW, Chen SK (1997) Natural recharge of groundwater in the areas from Tai-Shi to Mai-Lau, Taiwan (II), Department of Agricultural Engineering, National Taiwan University, Taipei, Taiwan, pp 30-45
Liu CW, Chen SK, Jou SW, Kuo SF (2001) Estimation of the infiltration rate of a paddy field in Yun-Lin, Taiwan. Agric Syst 68:41-54

McMennamy JA, O’Toole JC (1983) RICEMOD: A physiologically based rice growth and yield model. IRRI Research Paper 87, IRRI, Los Banos, Philippines

ten Berge HFM, Jansen DM, Rappoldt K, Stol W (1992) The soil water balance module SAWAH: User's guide and outline, CABO-TPE Simulation Reports, 22, CABO, Wageningen, Netherlands, pp 1-8

ten Berge HFM, Metselaar K, Jansen MJW, de San Agustin EM, Woodhead T (1995) The SAWAH riceland hydrology model. Water Resour Res 31:2721-2732

Tzia MH (1993) The contribution of rice paddy field irrigation to society in Taiwan, Council of Agriculture, Taiwan

Wickham TH, Singh VP (1978) Water movement through wet soil. In: Soil and rice, International Rice Research Institute, Los Banos, Philippines, pp 337-357

Wopereis MCS, Bouman BAM, Kroff MJ, ten Berge HFM, Maligaya AR (1994) Water use efficiency of flooded rice fields. (I) Validation of the soil-water balance model SAWAH. Agric Water Manage, 26:277-289 